\title{
PERAN EMPOWERMENT DALAM MEMODERASI PENGARUH KOMUNIKASI INTERPERSONAL TERHADAP IMPLEMENTASI INOVASI BEHAVIOR PADA KARYAWAN SARDINNE RESTAURANT
}

\author{
Ade Pramana Kusdi Putra ${ }^{1}$ \\ I Komang Ardana ${ }^{2}$ \\ ${ }^{1,2}$ Fakultas Ekonomi Universitas Udayanan (Unud), Bali, Indonesia \\ e-mail : adekusdi99@gmail.com
}

\begin{abstract}
ABSTRAK
Tujuan dari penelitian ini adalah untuk menguji peran empowerment dalam memoderasi pengaruh komunikasi interpersonal terhadap implementasi inovasi behavior pada karyawan Sardine Restaurant Seminyak Bali. Dalam penelitian ini digunakan metode sensus (total sampling) dalam menentukan sampel sebanyak 57 responden, melalui teknik analisis moderasi (MRA). Berdasarkan hasil analisis dapat diketahui bahwa komunikasi interpersonal memiliki pengaruh positif dan signifikan terhadap implementasi inovasi behavior pada karyawan Sardine Restaurant Seminyak Bali. Empowerment memiliki pengaruh positif dan signifikan terhadap implementasi inovasi behavior pada karyawan Sardine Restaurant Seminyak Bali. Empowerment mampu memoderasi hubungan positif komunikasi interpersonal terhadap implementasi inovasi behavior pada karyawan Sardine Restaurant Seminyak Bali. Saran yang direkomendasikan pihak manajemen harus melaksanakan empowerment menyangkut tingkah laku karyawan, maka dari itu perusahaan harus membina karyawannya dengan melakukan pembelajaran untuk menyelesaikan pekerjaan sehingga memiliki kreasi tersendiri dalam menyelesaikan pekerjaan baik itu di kitchen, weaters, booking table dalam meningkatkan.
\end{abstract}

Kata kunci : komunikasi interpersonal, empowerment, implementasi inovasi behavior

\begin{abstract}
The purpose of this study is to refresh the role of empowerment in moderating the influence of interpersonal communication on the implementation of behavioral innovation at the employees of Sardine Restaurant Seminyak Bali. In this study used the census method (total sampling) in determining the sample of 57 respondents, through moderation analysis techniques (MRA). Based on the results of the analysis can be seen that interpersonal communication has a positive and significant impact on the implementation of behavioral innovation in employees of Sardine Restaurant Seminyak Bali. Empowerment has a positive and significant influence on the implementation of behavioral innovation at the employees of Sardine Restaurant Seminyak Bali. Empowerment is able to moderate the positive relationship of interpersonal communication to the implementation of behavioral innovation at the employees of Sardine Restaurant Seminyak Bali. Suggestions that should be done empowerment related to employee behavior, therefore the company must foster its employees by doing learning to complete the work that has its own creations in completing the work either in the kitchen, biotic, ordering table in improving.

Keywords : interpersonal communication, empowerment, implementation innovation behavior
\end{abstract}


Ade Pramana Kusdi Putra, Peran Empoworment dalam.....

\section{PENDAHULUAN}

Pengembangan sektor kepariwisataan di suatu negara terbukti mampu memberikan distribusi yang signifikan terhadap sektor perekonomian negara. Perusahaan dituntut meningkatkan kualitas dan inovasi serta meningkatkan pelayanannya untuk dapat bersaing di pasar global, tak terkecuali bagi perusahaan jasa yang meliputi restauran, penginapan, dan transportasi (Manoela, 2013). Keberhasilan organisasi sangat tergantung pada kemampuannya dalam mengelola berbagai macam sumber daya yang dimiliki, terutama sumber daya manusia (SDM). SDM senantiasa melekat pada setiap sumber daya organisasi apapun sebagai faktor penentu keberadaan dan peranannya dalam memberikan konstribusi secara efektif dan efisien terhadap pencapaian tujuan organisasi (Pek dan Devie, 2014).

Sumber daya manusia (human resources) semakin penting untuk mensinergikan sumber daya lainnya dalam mencapai tujuan organisasi (Hasibuan, 2007:112). Perusahaan pada umumnya memiliki segala macam cara untuk meningkatkan kualitas karyawan dalam melaksanakan pekerjaan di perusahaan (Ahmad, 2014). Sumber daya manusia (SDM) pada masa ini dituntut agar mampu bersaing dengan mengembangkan potensi diri dalam hal inovasi dan kreatifitas. Kesuksesan suatu organisasi sangat ditentukan dari bagaimana organisasi tersebut mengelola sumber daya manusia (SDM) di perusahaan (Hendri, 2015).

Keberadaan industri pariwisata sebagai bagian dari sektor ekonomi merupakan industri yang sangat menjanjikan dalam menghadapi persaingan 
industri pada abad ini, fenomena tersebut didasarkan atas kenyataan bahwa berkembangnya teknologi dan semakin tingginya tingkat kesejahteraan.

Masyarakat telah mendorong pertumbuhan yang sangat pesat pada tingkat mobilitas wisatawan internasional maupun domestik. Industri pariwisata berpengaruh untuk meningkatkan perekonomian di suatu negara. Berkembangnya teknologi dan padatnya mobilitas warga domestik maupun internasional membutuhkan wisata hiburan sehingga kondisi seperti ini dapat memicu pertumbuhan industri-industri sampingan yang menunjang berkembangnya industri pariwisata, industri sampingan tersebut seperti restoran, travel, factory outlet dan perhotelan.

Sardinne restaurant Seminyak Bali adalah salah satu usaha wisata kuliner dengan menawarkan menu hidangan bernuansa westin eropa dilengkapi suasana pemandangan, yang merupakan perubahan drastis dari keramaian dan hiruk pikuk jalan raya Seminyak. Ruang makan terbuka yang menghadap ke sawah dirancang indah dengan unsur-unsur lokal sehingga terkesan ramah lingkungan. Menawarkan menu-menu khusus sarat dengan pilihan makanan vegetarian yang dikombinasi dengan menu-menu eropa seperti chilled gazpaco with avocado, small green salad with avocado, mediterranean green salad with calamari, salad nicoise, thai spiced salad on green papaya salad dan masih banyak lagi menu yang lainnya yang disajikan dengan bungkus daun pisang sebagai hidangan favorit dengan dessert sampler dan kelapa jack buah es krim semua dihidangkan untuk menarik minat pelanggan. Sardine restaurant berdiri sendiri dengan 57 staf yang ramah dan penuh perhatian dalam memberikan pelayanan pada wisatawan, 
jumlah staf Sardine restaurant dapat dilihat pada Tabel 1 yang selama ini mendukung jalannya operasional perusahaan.

Tabel 1.

Jumlah Karyawan Pada Sardine Restaurant Seminyak Bali

\begin{tabular}{ccc}
\hline No & Bagian & $\begin{array}{c}\text { Jumlah Karyawan } \\
\text { (Orang) }\end{array}$ \\
\hline 1 & Manager & 1 \\
2 & Accounting & 5 \\
3 & Marketing Department & 6 \\
4 & Human Resource & 6 \\
5 & Restaurant Manager & 2 \\
6 & Food and Kicthen & 10 \\
7 & Waiter & 14 \\
8 & Steward & 9 \\
9 & Security & 4 \\
\hline & Jumlah & $\mathbf{5 7}$ \\
\hline
\end{tabular}

Sumber : Sardine Restaurant, 2017

Tabel 1 dapat diketahui jumlah karyawan Sardine restaurant sebanyak 57 orang. Karyawan terbanyak terdapat pada bagian waiter sebanyak 14 orang dan jumlah karyawan terkecil pada security masing-masing sebanyak 4 orang. Tujuan dicantumkan tabel ini adalah untuk mengetahui banyaknya karyawan (tenaga kerja) yang ada pada Sardine Restaurant yang membantu kelancaran operasional perusahaan dalam mencapai tujuannya. Perkembangan dunia bisnis pariwisata di Indonesia pada saat ini, khususnya Bali dalam menjual jasa pelayanan akomodasi pariwisata yang berhubungan dengan restaurant dirasakan semakin pesat.

Perkembangan Sardine restaurant belakangan ini berdasarkan transaksi penjualan mengalami penurunan. Hal ini dapat dikatakan kurang efektif dan efisien pencapain kerja karyawan. Perkembangan penjualan Sardine restaurant dari tahun 2012 sampai tahun 2016 dapat dilihat pada Tabel 2. 
Tabel 2.

Target dan Total Transaksi Penjualan Sardine Restaurant Periode Tahun 2011-2016

\begin{tabular}{cccc}
\hline Tahun & $\begin{array}{c}\text { Target Transaksi Penjualan } \\
\text { (Milyar Rupiah) }\end{array}$ & $\begin{array}{c}\text { Total Transaksi Penjualan } \\
\text { (Milyar Rupiah) }\end{array}$ & Pertumbuhan (\%) \\
\hline 2012 & 5.040 .000 .000 & 4.972 .000 .000 & - \\
2013 & 5.580 .000 .000 & 5.210 .000 .000 & 4,78 \\
2014 & 6.120 .000 .000 & 5.120 .000 .000 & $(1,72)$ \\
2015 & 6.480 .000 .000 & 6.280 .000 .000 & 22,65 \\
2016 & 7.200 .000 .000 & 6.980 .000 .000 & 11,1 \\
\hline
\end{tabular}

Sumber : Sardine restaurant, 2017

Tabel 2 dapat diketahui total penjualan layanan jasa penginapan (kamar) dari tahun 2012 - 2016 cenderung berfluktuasi, ini disebabkan oleh kurangnya dukungan kerja karyawan yang tidak optimal dalam memasarkan produk dan jasa Sardine restaurant. Terlihat bahwa peningkatan transaksi penjualan Sardine restaurant tidak terlalu signifikan dan dapat dilihat penjualan pernah mengalami penurunan sangat signifikan yaitu sebesar $(1,72)$ persen pada tahun 2014 , selain adanya persaingan yang ketat, hal ini dapat disebabkan oleh kurangnya support dari karyawan dengan inovasi-inovasi yang dikembangkan, karyawan tidak optimal dalam memasarkan dan menawarkan produk Sardine restaurant. Masalah ini menunjukkan indikasi adanya masalah terhadap minimnya sikap implementasi inovasi behavior karyawan sehingga terjadinya penurunan transaksi penjualan Sardine restaurant.

Menghadapi ketatnya persaingan antar restoran di Bali membuat restoranrestoran yang ada dituntut untuk memberikan pelayanan terbaik terhadap para wisatawan sebagai konsumennya. Implementasi inovasi behavior pada karyawan merupakan hal terpenting untuk mewujudkan tujuan perusahaan dalam memberikan rasa nyaman dan puas bagi pelanggannya, banyak perusahaan yang mengalami penurunan produktivitas perusahaannya yang disebabkan oleh 
Ade Pramana Kusdi Putra, Peran Empoworment dalam.....

implementasi inovasi behavior karyawannya tidak terpenuhi dalam mengembangkan ide-ide kreatifnya dan inovasi-inovasinya di dalam bekerja (Kurnia, 2015). Keberhasilan tercapainya tujuan perusahaan tergantung pada kemampuan dan keahlian karyawan dalam melaksanakan fungsi perusahaan yang berkaitan dengan fungsi personalia atau SDM dalam menerapkan pemberdayaan serta komunikasi yang efektif secara berkesinambungan (Ari, 2006).

Barbara et al. (2014) menjelaskan organisasi memegang kunci yang sangat penting dalam membantu karyawan untuk membangun implementasi inovasi behavior. Implementasi inovasi mengacu pada proses dimana karyawan menjadi mampu dan berkomitmen untuk menggunakan inovasi tertentu. Karyawan harus mengadopsi implementasi inovasi berdasarkan keputusan yang biasanya dibuat oleh seorang manajer di dalam organisasi. Karyawan diharapkan dalam organisasi akan menggunakan implementasi inovasi dalam melaksanakan pekerjaanya untuk membantu perusahaan dalam menjalankan operasionalnya (Klein dan Sorra, 1996). Kegagalan implementasi terjadi apabila keterkaitan ini tidak sejalan dengan apa yang di sampaikan oleh seorang pimpinan, karyawan tidak terlibat dalam inovasi atau secara konsisten seperti potensi dan manfaat untuk direalisasikan dalam pekerjaannya tidak berjalan sesuai rencana (Astohar, 2012).

Faktor yang dapat membangun implementasi inovasi behavior adalah komunikasi interpersonal (Hasan et al., 2010). Hal yang sangat mempengaruhi kemampuan suatu organisasi untuk bersaing dalam iklim bisnis yang sangat sulit adalah menjalin komunikasi interpersonal yang efektif (Kurnia, 2015). Komunikasi merupakan hal yang sangat vital dalam mempengaruhi 
perkembangan diri seseorang, semua sifat tingkah laku serta perilaku seseorang terbentuk oleh proses komunikasi dan di pengaruhi oleh orang orang terdekat seperti keluarga, rekan kerja dan sahabat serta pengaruh media yang sedang berkembang saat ini (Lora, 2015).

Hakekatnya komunikasi interpersonal adalah komunikasi antara komunikator dengan komunikan. Komunikasi jenis ini dianggap paling efektif dalam upaya mengubah sikap, pendapat atau perilaku seseorang, karena sifatnya yang dialogis berupa percakapan (Kurnia, 2015). Arus balik dari komunikasi ini bersifat langsung, dimana komunikator mengetahui tanggapan komunikan ketika itu juga (Orebiyi, 2011). Pada saat komunikasi dilancarkan, komunikator mengetahui secara pasti apakah komunikasinya positif atau negatif, berhasil atau tidak jika ia dapat memberikan kesempatan pada komunikan untuk bertanya seluas-luasnya. Artinya, dalam komunikasi interpersonal tidak hanya terjadi komunikasi satu arah, melainkan terjadi komunikasi timbal balik atau dua arah (Manoela, 2013). Para anggota diharapkan selalu menciptakan komunikasi interpersonal yang berkualitas agar semakin efektif pula hubungan yang terjadi di antara mereka, karena melalui komunikasi interpersonal yang efektif dan berkualitas dapat membentuk dan memperkuat sikap positif anggota sebagai bentuk dari implementasi inovasi behavior. Beberapa penelitian menunjukkan pengaruh positif antara komunikasi interpersonal dengan implementasi inovasi behavior. Penelitian Kurnia (2015) menyatakan komunikasi interpersonal memiliki pengaruh positif terhadap implementasi inovasi behavior. Hal yang sama dinyatakan oleh Hasan et al. (2010) inovasi kreatif karyawan dapat 
Ade Pramana Kusdi Putra, Peran Empoworment dalam.....

dipengaruhi oleh komunikasi interpersonal secara positif. Manoela (2013) dalam penelitiannya membukitkan ada keterkaitan positif antara komunikasi interpersonal dengan implementasi inovasi behavior.

Employee empowerment merupakan faktor penting dalam menciptakan keunggulan bersaing perusahaan seperti yang dinyatakan oleh (Conger \& Kanungo, 1988) yang menyatakan pengembangan inovasi terhadap suatu produk yang mengarah pada kreativitas di dalam organisasi dapat diciptakan dengan adanya empowerment. Pemberdayaan merupakan wewenang untuk membuat keputusan dalam suatu area kegiatan operasi tertentu tanpa harus memperoleh pengesahan orang lain (Luthans, 2011). Pemberdayaan adalah pemberian wewenang kepada karyawan untuk merencanakan (planning), mengendalikan (controlling) dan membuat keputusan atas pekerjaan yang menjadi tanggung jawabnya tanpa harus mendapatkan otorisasi secara eksplisit dari atasannya (Kok Pooi, 2011). Pemberdayaan merupakan alat yang dilakukan perusahaan sebagai rangsangan dalam meningkatkan motivasi serta komitmen karyawan (Rahmawati et al., 2014). Karyawan akan mengeluarkan semua potensi yang ada dalam dirinya melalui pemberdayaan sehingga meningkatkan motivasi berdasarkan komitmennya terhadap perusahaan. Barbara et al. (2014) dalam penelitiannya menunjukkan lima aspek pemberdayaan psikologis memberikan dampak positif dan berkorelasi dengan motivasi intrinsik komitmen karyawan yang diterapkan dengan dalam bentuk implementasi inovasi behavior. Muhdar et al. (2015) menyatakan dalam penelitiannya empowerment memiliki keterkaitan positif pada implementasi inovasi behavior. Hakan dan Jamel (2015) empowerment sebagai 
variabel mediasi memberikan pengaruh positif terhadap implementasi inovasi behavior. Rella et al. (2015) menyatakan empowerment mampu memediasi secara positif peningkatan inovasi karyawan secara kreatif di dalam perusahaan.

Dimensi yang memiliki keterkaitan dengan implementasi inovasi yang melibatkan hubungan, pertama ketika komunikasi interpersonal membentuk ikatan interpersonal dengan pengikutnya. Kedua, memberdayakan pengikut (termasuk masukan follower di keputusan manajerial penting). Empowerment juga membantu pengikut untuk tumbuh dan berhasil dengan memberikan kesempatan dalam meningkatkan keterampilan follower. Ketiga, empowerment berperilaku secara etis (Izani dan Yahya, 2014), misalnya, karyawan yang diberikan kesempatan untuk jabatan yang lebih baik akan menindaklanjuti janjijanji yang dibuat untuk pengikut untuk menunjukkan ketaatan mereka terhadap nilai-nilai etis yang kuat di dalam organisasi. Ke empat, empowerment mengajarkan karyawan untuk menunjukkan keterampilan konseptual, seperti menyeimbangkan pekerjaan sehari-hari dengan visi masa depan. Akhirnya, empowerment memberikan dorongan karyawan untuk terlibat dalam kesempatan melaksanakan kegiatan sosial di masyarakat di luar pekerjaan (Muhdar et al., 2015).

Fenomena masalah yang menyangkut implementasi inovasi behavior karyawan pada Sardine restaurant ditunjukkan dengan sikap karyawan yang kurang kreatif dalam mengumpulkan informasi sebagai pembelajaran melalui komunikasi interpersonal yang masih dirasakan rendah karena tidak memanfaatkan sumber-sumber sebagai pembelajaran dalam mengerjakan 
Ade Pramana Kusdi Putra, Peran Empoworment dalam.....

pekerjaan yang diberikan (Bjorn et al., 2009). Karyawan tidak mengetahui informasi untuk mengurangi ambiguitas yang berkaitan dengan pekerjaan. Kurangnya penyampaian informasi melalui kontak pribadi, telepon percakapan, memorandum tertulis, surat, laporan khusus, rantai formal perintah, serta beberapa media modern seperti konferensi video, surat elektronik, atau internet agar mudah dimengerti karyawan (David and Susan, 2010). Rendahnya implementasi inovasi behavior pada karyawan dapat disebabkan oleh beberapa faktor, antara lain minimnya komunikasi interpersonal yang terjalin serta kurangnya pemberdayaan yang terlaksanakan (Rella dan Mohamad, 2014).

Perilaku-perilaku tersebut merupakan tindakan yang tidak mendukung efektivitas dan efisiensi dalam bekerja. Karyawan melakukan hal menyimpang atau melanggar, yang menunjukkan tanggungjawab yang rendah pada pekerjaan. Jika keadaan ini dibiarkan terus-menerus tanpa adanya perubahan yang dilakukan, akan berdampak pada menurunnya efektivitas dan produktivitas di Sardine restaurant. Perlu adanya peran dari pimpinan, karyawan dan seluruh anggota perusahaan menjalin komunikasi interpersonal dan pentingnya kesempatan pemberdayaan atau empowerment pada karyawan sehingga mengurangi rendahnya implementasi inovasi behavior karyawan.

Penelitian ini terkonsentrasi pada identifikasi variabel perbedaan individual dimana komunikasi interpersonal dan empowerment terkait dengan perilaku implementasi inovasi. Dalam konteks ini, studi ini menarik untuk diteliti dengan tinjauan literatur komunikasi interpersonal dan empowerment, perilaku inovasi kreatif karyawan pada perusahaan. 
Implementasi inovasi mengacu pada proses dimana karyawan menjadi mampu dan berkomitmen untuk menggunakan inovasi tertentu, yang artinya karyawan harus mengadopsi inovasi berdasarkan keputusan yang biasanya dibuat oleh seorang manajer di dalam organisasi, diharapkan karyawan dalam organisasi akan menggunakan inovasi dalam melaksanakan pekerjaanya (Klein dan Sorra, 1996). Kegagalan implementasi terjadi apabila keterkaitan ini tidak sejalan dengan apa yang di sampaikan oleh seorang pimpinan, karyawan tidak terlibat dalam inovasi atau secara konsisten seperti potensi dan manfaat untuk direalisasikan dalam pekerjaannya tidak berjalan sesuai rencana. Implementasi inovasi mengadopsi inovasi berdasarkan keputusan yang biasanya dibuat oleh seorang manajer di dalam organisasi antara lain (Hakan dan Jamel, 2015).

Devito (2011:75) Komunikasi (communication) berasal dari bahasa latin yaitu dari kata communication yang artinya menyapa, dimana komunikator berusaha menetapkansuatu kebersamaan (commones) dengan penerima. Jadi apabila kita akan mengadakan komunikasi dengan pihak lain, maka harus menentukan terlebih dahulu suatu sasaran sebagai dasar untuk memperoleh pengertian yang sama (Syahfarnas, 2014).

Menurut Kamus Besar Bahasa Indonesia (2008), yang dimaksud dengan komunikasi adalah pengiriman dan penerimaan pesan atau berita antara dua orang atau lebih sehingga pesan yang dimaksud dapat dipahami. Tidak jauh berbeda dari definisi di atas, di pada Kamus Psikologi (Syahfarnas, 2014), komunikasi didefinisikan sebagai segala penyampaian energi, gelombang suara dan tanda diantara tempat sebagai proses penyampaian suatu pesan dalam bentuk lambing 
bermakna sebagai paduan pikiran dan perasaan berupa ide, informasi, kepercayaan, harapan, imbauan, dan sebagainya, yang dilakukan seseorang kepada orang lain, baik langsung secara tatap muka maupun tidak langsung melalui media dengan tujuan mengubah sikap, pandangan atau perilaku.

Robbins (2008:112) menyatakan pemberdayaan merupakan menempatkan pekerjaan bertanggung jawab atas apa yang mereka kerjakan. Memberdayakan orang berarti mendorong mereka menjadi lebih terlibat dalam keputusan dan aktivitas yang mempengaruhi pekerjaan mereka (Eko, 2012). Seorang karyawan memiliki wewenang dan berinisiatif untuk melakukan sesuatu yang dipandang perlu, jauh melebihi tugasnya sehari-hari (Kok Pooi, 2011). Pemberdayaan merupakan wewenang untuk membuat keputusan dalam suatu area kegiatan operasi tertentu tanpa harus memperoleh pengesahan orang lain (Luthans, 2011). Pemberdayaan karyawan merupakan pemberian wewenang kepada karyawan untuk merencanakan (Planning), mengendalikan (Controlling) dan membuat keputusan atas atas pekerjaan yang menjadi tanggung jawabnya tanpa harus mendapatkan otorisasi secara eksplisit dari manajer diatasya (Hansen and Mowen, 2009). Pada penelitian (Spreitzer, 1995) dikemukan empat karakteristik umum yang dilimiki empowered people yang juga sama dengan konsep Thomas dan Velthouse (1990).

Model pemberdayaan yang dapat dikembangkan dalam sebuah organisasi untuk menjamin keberhasilan proses pemberdayaan dalam suatu organisasi (Khan, 1997). Model pemberdayaan tersebut adalah sebagai berikut. 1). Desire, 2). Trust, 3). Confident, 4). Credibility, 5). Accountability, 6). Communication. 
Tujuan yang dilakukan dalam penelitian ini yaitu: 1. Untuk menganalisis pengaruh komunikasi interpersonal terhadap implementasi inovasi behavior karyawan di Sardine restaurant, 2. Untuk menganalisis peran empowerment memoderasi pengaruh komunikasi interpersonal terhadap implementasi inovasi behavior karyawan di Sardine restaurant.

\section{METODE PENELITIAN}

Berdasarkan permasalahan yang diteliti, penelitian ini digolongkan pada penelitian asosiatif (hubungan), yaitu penelitian yang bertujuan untuk mengetahui hubungan dari variabel atau lebih (Sugiyono, 2013 :5) penelitian asosiatif ini juga digunakan oleh (Hendri dan Devie, 2015) dalam penelitiannya. Dalam penelitian ini jenis hubungannya adalah hubugan linier karena bertujuan untuk mengetahui variabel-variabel yang mempengaruhi implementasi inovasi behavior karyawan. Penelitian dilakukan di Sardinne Restaurant Seminyak Bali, Jalan Petitenget No. 21, Kerobokan, Kuta Bali tahun 2017. Obyek penelitian adalah peran empowerment memoderasi pengaruh komunikasi interpersonal terhadap implementasi inovasi behavior pada karyawan Sardinne Restaurant Seminyak Bali.

Variabel terikat dalam penelitian ini adalah dalam penelitian ini adalah komunikasi interpersonal. Komunikasi interpersonal menurut De Vito (dalam Syahfarnas, 2014) menjelaskan bahwa komunikasi interpersonal merupakan pengiriman pesan-pesan dari seseorang dan diterima oleh orang lain atau sekelompok orang dengan efek dan umpan balik yang langsung. 
Ade Pramana Kusdi Putra, Peran Empoworment dalam.....

Empowerment merupakan variabel pemoderasi dalam penelitian. Empowerment menurut Randolph (2000) dalam Hendri (2015) menyatakan bahwa empowerment bukan hanya sekedar memberi kebebasan kepada orang lain untuk memutuskan, namun empowerment adalah kekuasaan yang intelijen untuk pengambilan keputusan untuk membantu perusahaan menjalankan aktivitas yang effektif.

Sumber data yang digunakan dalam penelitian ini menggunakan data primer. Data Primer adalah data yang diperoleh secara langsung dari Sardine restauran, diamati dan dicatat untuk pertama kalinya oleh peneliti, data ini didapatkan dengan observasi dan pemberian kuesioner kepada responden yaitu karyawan Sardine restaurant. Populasi dan sampel dalam penelitian ini adalah karyawan Sardine restauran sebanyak 57 orang.

Teknik analisis data yang digunakan dalam penelitin ini adalah analisis regresi linear berganda. Teknik analisis data yang diterapkan dalam penelitian ini dilakukan secara kuantitatif dengan penekanan data yang bersumber dari data primer, yang mana data tersebut akan diolah kemudian dianalisis. Di samping itu, analisis data akan dilakukan secara kuantitatif dengan menerapkan landasan teori sehingga diharapkan akan memperoleh kesimpulan yang berbobot ilmiah.

Setelah data-data yang dibutuhkan diperoleh, selanjutnya dilakukan analisis sehingga data tersebut lebih berarti. Teknik perhitungan dan analisis data menggunakan Moderating Regression Analysis. Moderating Regression Analysis dinyatakan dalam bentuk regresi berganda dengan persamaan mirip regressi 
polynomial yang menggambarkan pengaruh nonlinier (Ghozali, 2011; 47) yang dinyatakan dalam bentuk model persamaan sebagai berikut.

$$
\begin{aligned}
& \mathrm{Y}=\alpha+\beta_{1} \mathrm{X}_{1+\beta_{2}}\left(\mathrm{X}_{1} \mathrm{M}\right)+\mathrm{e} \\
& \text { Keterangan: } \\
& \text { Y = implementasi inovasi behavior } \\
& \alpha \quad=\text { konstanta } \\
& \beta_{1}, \beta_{2}, \quad=\text { Koefisien regresi masing-masing variabel independen } \\
& \mathrm{X}=\text { komunikasi interpersonal } \\
& \mathrm{M}=\text { empowerment } \\
& \text { e } \quad=\text { error term yaitu faktor kesalahan dalam penelitian }
\end{aligned}
$$

\section{PEMBAHASAN HASIL PENELITIAN}

Sebuah instrumen dikatakan valid jika mampu mengukur apa yang seharusnya diukur, dan dapat mengungkap data dari variabel yang diteliti secara tepat. Syarat minimum untuk dianggap memenuhi syarat adalah kalau $r=0,3$ ”. Jadi kalau korelasi antara butir skor dengan skor total kurang dari 0,3 maka butir dalam instrumen tersebut dinyatakan tidak valid. Adapun hasil uji validitas dapat dilihat pada Tabel 3 berikut.

Tabel 3 dapat dijelaskan bahwa masih-masing indikator variabel memiliki nilai person correlation lebih besar dari 0,30 , maka ini berarti indikator/pertanyaan yang digunakan layak digunakan untuk mengukur apa yang seharusnya diukur, dan dapat mengungkap data dari variabel yang diteliti secara tepat.

Tabel 4 menjelaskan bahwa nilai Cronbach's Alpha untuk masing-masing variabel > 0,6, ini berarti alat ukur tersebut akan memberikan hasil yang konsisten apabila alat ukur tesebut digunakan kembali untuk meneliti obyek yang sama. 
Tabel 3.

Rangkuman Hasil Uji Validitas

\begin{tabular}{clccc}
\hline No & Variabel & Indikator & Korelasi & Keterangan \\
\hline 1 & Implementasi inovasi behavior $(\mathrm{Y})$ & Y1 & 0,786 & Valid \\
& & Y2 & 0,686 & Valid \\
& & Y3 & 0,753 & Valid \\
\multirow{2}{*}{2} & \multirow{4}{*}{ Komunikasi interpersonal $(\mathrm{X})$} & $\mathrm{Y} 4$ & 0,856 & Valid \\
& & $\mathrm{X} 1.1$ & 0,693 & Valid \\
& & $\mathrm{X} 1.2$ & 0,750 & Valid \\
& & $\mathrm{X} 1.3$ & 0,722 & Valid \\
& & $\mathrm{X} 1.4$ & 0,713 & Valid \\
& \multirow{2}{*}{ Empowerment $(\mathrm{M})$} & $\mathrm{X} 1.5$ & 0,692 & Valid \\
& & $\mathrm{M} 1.1$ & 0,845 & Valid \\
& & $\mathrm{M} 1.2$ & 0,664 & Valid \\
& & $\mathrm{M} 1.3$ & 0,835 & Valid \\
& & $\mathrm{M} 1.4$ & 0,775 & Valid \\
\hline
\end{tabular}

Sumber : Hasil Olahan SPSS, 2018 (Lampiran 3)

Tabel 4.

\section{Hasil Uji Reliabilitas}

\begin{tabular}{clcc}
\hline \multirow{2}{*}{ No } & \multicolumn{1}{c}{ Variabel } & $\begin{array}{c}\text { Cronbach's } \\
\text { Alpha }\end{array}$ & Keterangan \\
\hline 1 & Implementasi inovasi behavior $(\mathrm{Y})$ & 0,771 & Reliabel \\
2 & Komunikasi interpersonal $(\mathrm{X})$ & 0,759 & Reliabel \\
3 & Empowerment $(\mathrm{M})$ & 0,789 & Reliabel \\
\hline
\end{tabular}

Sumber: Hasil Olahan SPSS, 2018 (Lampiran 4)

Jumlah responden yang dijadikan sampel data penelitian di Sardine Restaurant Seminyak Bali adalah sebanyak 58 orang menyangkut penilaian tentang peran empowerment memoderasi pengaruh komunikasi interpersonal terhadap implementasi inovasi behavior. Penelitian kualitatif dipergunakan skor rata-rata jawaban responden dengan kriteria dan kategori penilaian jawaban kuisioner. Terdapat formulasi untuk mencari nilai interval yaitu:

$$
\text { Interval }=\frac{\text { Skortertinggi-skorterendah }}{\text { jumlahkelas }}
$$

Mengingat skor untuk masing-masing alternatif jawaban untuk variabel pada penelitian ini adalah minimal skornya adalah 1 dan maksimal adalah 5, maka di dapatlah perhitungan interval dengan menggunakan rumus di atas adalah Interval $=\frac{b-1}{b}$ Nilai intervalnya adalah $=0,8$, untuk mengetahui penilaian 
variabel-variabel penelitian secara menyeluruh akan dapat dilihat dari rata-rata skor dengan kriteria tercermin pada Tabel 5.

Table 5.

Hasil Penilaian Responden atas Variabel Komunikasi Interpersonal

\begin{tabular}{|c|c|c|c|c|c|c|c|c|c|}
\hline \multirow{2}{*}{ No } & \multirow{2}{*}{ Pernyataan } & \multicolumn{5}{|c|}{ jawaban } & \multirow{2}{*}{$\begin{array}{l}\text { Total } \\
\text { Skor }\end{array}$} & \multirow{2}{*}{$\begin{array}{c}\text { Rata-rata } \\
\text { Skor }\end{array}$} & \multirow{2}{*}{$\begin{array}{l}\text { Kategori } \\
\text { penilaian }\end{array}$} \\
\hline & & STS & TS & $\mathrm{N}$ & $\mathrm{S}$ & SS & & & \\
\hline 1 & $\begin{array}{l}\text { Saya tidak merasa } \\
\text { malu dalam } \\
\text { berkomunikasi }\end{array}$ & 1 & 8 & 6 & 25 & 17 & 220 & 3.86 & Baik \\
\hline 2 & $\begin{array}{l}\text { Saya selalu } \\
\text { menerima informasi } \\
\text { yang jelas }\end{array}$ & 0 & 2 & 8 & 29 & 18 & 234 & 4.11 & Baik \\
\hline 3 & $\begin{array}{l}\text { Saya selalu } \\
\text { mengatur } \\
\text { pembicaraan secara } \\
\text { konsisten }\end{array}$ & 0 & 4 & 19 & 12 & 22 & 223 & 3.91 & Baik \\
\hline 4 & $\begin{array}{l}\text { Saya } \\
\text { berkomunikasi } \\
\text { dengan } \\
\text { memberikan umpan } \\
\text { balik yang relevan }\end{array}$ & 2 & 10 & 19 & 15 & 11 & 194 & 3.40 & Baik \\
\hline 5 & $\begin{array}{l}\text { Saya selalu } \\
\text { menghargai } \\
\text { perbedaan dengan } \\
\text { orang lain }\end{array}$ & 2 & 13 & 20 & 14 & 8 & 184 & 3.23 & Baik \\
\hline & & $\begin{array}{l}\text { umla } \\
\text { i-rata }\end{array}$ & & & & & $\begin{array}{c}1055 \\
211 \\
\end{array}$ & $\begin{array}{c}18,51 \\
3,70\end{array}$ & $\begin{array}{l}\text { Baik } \\
\text { Baik }\end{array}$ \\
\hline
\end{tabular}

Tabel 5 menjelaskan persepsi responden mengenai variabel komunikasi interpersonal dilihat dari pernyataan ke dua, saya selalu menerima informasi yang jelas memiliki nilai rata-rata skor tertinggi yaitu 4,11 persen. Sedangkan dari pernyataan kelima, saya selalu menghargai perbedaan dengan orang lain, memiliki nilai rata-rata skor terendah yaitu 3,23 persen. Diperoleh nilai total rata-rata jawaban responden sebesar 3,70 dalam kategori baik, maka ini berarti secara keseluruhan karyawan Sardine Restaurant memberikan respon terhadap komunikasi interpersonal. Terlihat indikasi permasalahan komunikasi interpersonal dari karyawan minimnya rasa kerja sama dalam hal saling menghargai satu sama lain, hal ini harus segera di atasi oleh pihak manajemen 
Ade Pramana Kusdi Putra, Peran Empoworment dalam.....

dalam hal melakukan pertemuan-pertemuan rutin, mengadakan family gathering sehingga satu sama lain karyawan lebih mengenal dengan komunikasi yang baik untuk menciptakan rasa saling menghargai dalam melaksanakan pekerjaan.

Table 6.

Hasil Penilaian Responden atas Variabel Empowerment

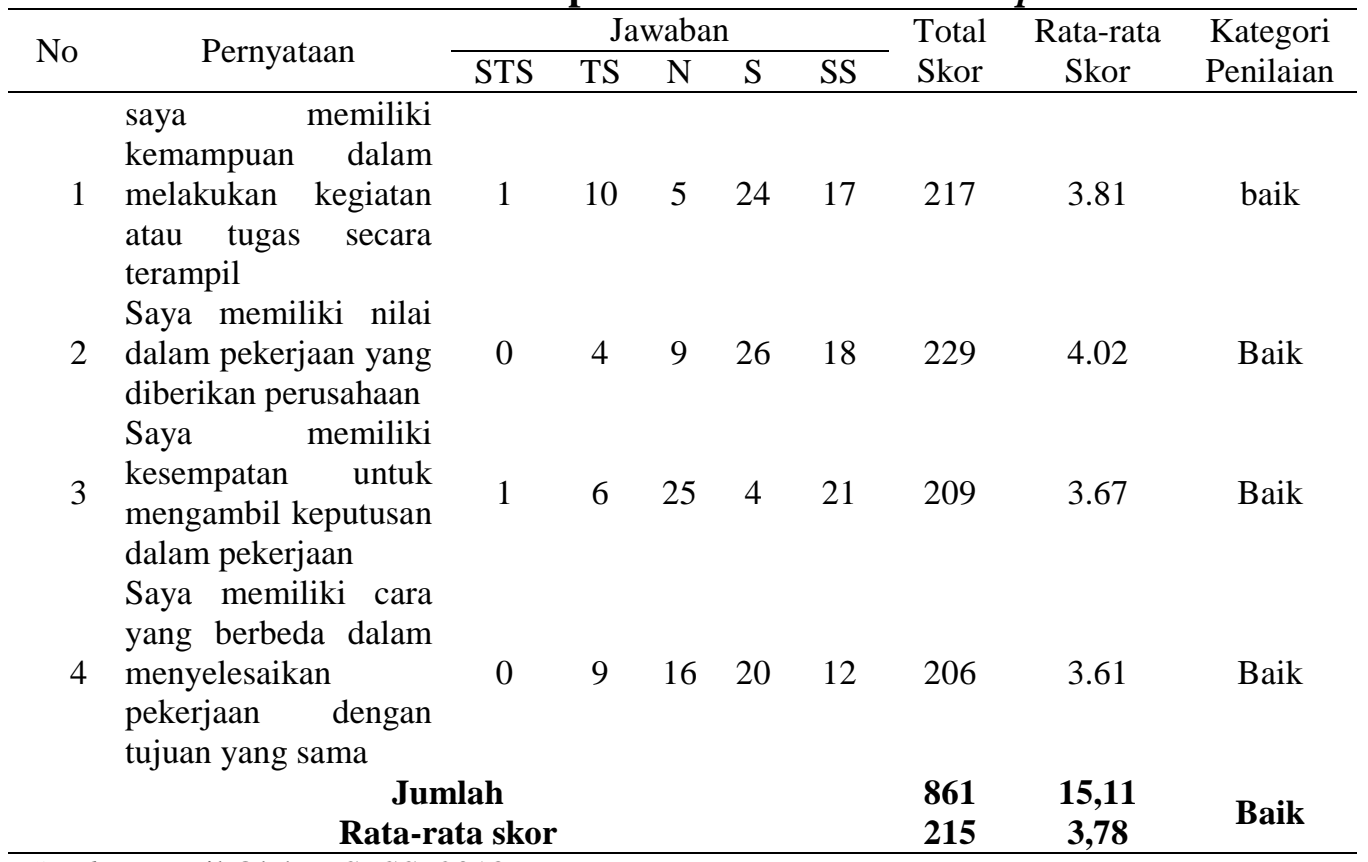

Sumber: Hasil Olahan SPSS, 2018

Tabel 6 menjelaskan persepsi responden mengenai variabel empowerment di lihat dari pernyataan ke dua, saya memiliki nilai dalam pekerjaan yang diberikan perusahaan memiliki nilai rata-rata skor tertinggi yaitu 4,02 persen. Sedangkan dari pernyataan ke empat, saya memiliki cara yang berbeda dalam menyelesaikan pekerjaan dengan tujuan yang sama, memiliki nilai rata-rata skor terendah yaitu 3,61 persen. Diperoleh nilai total rata-rata jawaban responden sebesar 3,78 dalam kategori baik, maka ini berarti secara keseluruhan karyawan Sardine Restaurant memberikan respon terhadap empowerment. Indikasi permasalahan yang dihadapi karyawan dalam pelaksanaan empowerment menyangkut tingkah laku karyawan, maka dari itu perusahaan harus membina 
karyawannya dengan melakukan pembelajaran untuk menyelesaikan pekerjaan sehingga memiliki kreasi tersendiri dalam menyelesaikan pekerjaan baik itu di kitchen, weaters, booking table dll.

Tabel 7.

Hasil Uji Kolmogorov-Smirnov

One-Sample Kolmogorov-Smirnov Test

\begin{tabular}{|c|c|c|}
\hline & & $\begin{array}{l}\text { Unstandardized } \\
\text { Residual }\end{array}$ \\
\hline $\mathrm{N}$ & & 57 \\
\hline \multirow{2}{*}{ Normal Parameters(a,b) } & Mean & 0,0570484 \\
\hline & Std, Deviation & 0,87840700 \\
\hline \multirow[t]{3}{*}{ Most Extreme Differences } & Absolute & 0,120 \\
\hline & Positive & 0,120 \\
\hline & Negative & $-0,104$ \\
\hline Kolmogorov-Smirnov Z & & 0,908 \\
\hline Asymp. Sig. (2-tailed) & & 0,382 \\
\hline
\end{tabular}

Uji normalitas ini dilakukan untuk menguji apakah dalam sebuah model regresi (variabel dependen dan variabel independen ataupun keduanya) memiliki distribusi normal atau tidak. Pengujian normalitas nilai residual dalam penelitian ini dilakukan dengan menggunakan metode Kolmogorov-Smirnov. Data dikatakan berdistribusi normal jika taraf signifikansi lebih besar dari 0,05. Dari Lampiran 6 diketahui nilai signifikansi sebesar 0,382 $(0,382>0,05)$. Hal ini berarti model regresi berdistribusi normal.

Tabel 8.

\section{Hasil Uji Multikolinearitas} coefficients $^{\mathrm{a}}$

\begin{tabular}{lcc}
\hline \multicolumn{1}{c}{ Variabel } & Tolerance & VIF \\
\hline Komunikasi interpersonal $(\mathrm{X})$ & 0,920 & 1,087 \\
Empowerment $(\mathrm{M})$ & 0,921 & 1,096 \\
\hline
\end{tabular}

Sumber: Data Primer Diolah, 2018

Berdasarkan Tabel 8 dapat dilihat bahwa nilai tolerence masing-masing variabel lebih besar dari 0,1 dan nilai VIF lebih kecil dari 10, sehingga dapat 
disimpulkan bahwa dalam model regresi tidak terjadi multikolinearitas dan dapat digunakan dalam penelitian.

Tabel 9.

Hasil Uji Heteroskedastisitas coefficients $^{\mathrm{a}}$

\begin{tabular}{lcc}
\hline \multicolumn{1}{c}{ Variabel } & Sig. & Keterangan \\
\hline Komunikasi interpersonal $(\mathrm{X})$ & 0,085 & Bebas heteroskedastisitas. \\
Empowerment $(\mathrm{M})$ & 0,541 & Bebas heteroskedastisitas \\
\hline Sumber: Data Primer Diolah, 2018 & &
\end{tabular}

Berdasarkan Tabel 9 dapat dilihat bahwa nilai sig. masing-masing variabel lebih besar dari 0,05 yang berarti variabel tersebut bebas heteroskedastisitas.

Tabel 10.

Hasil Pelaporan Analisis MRA

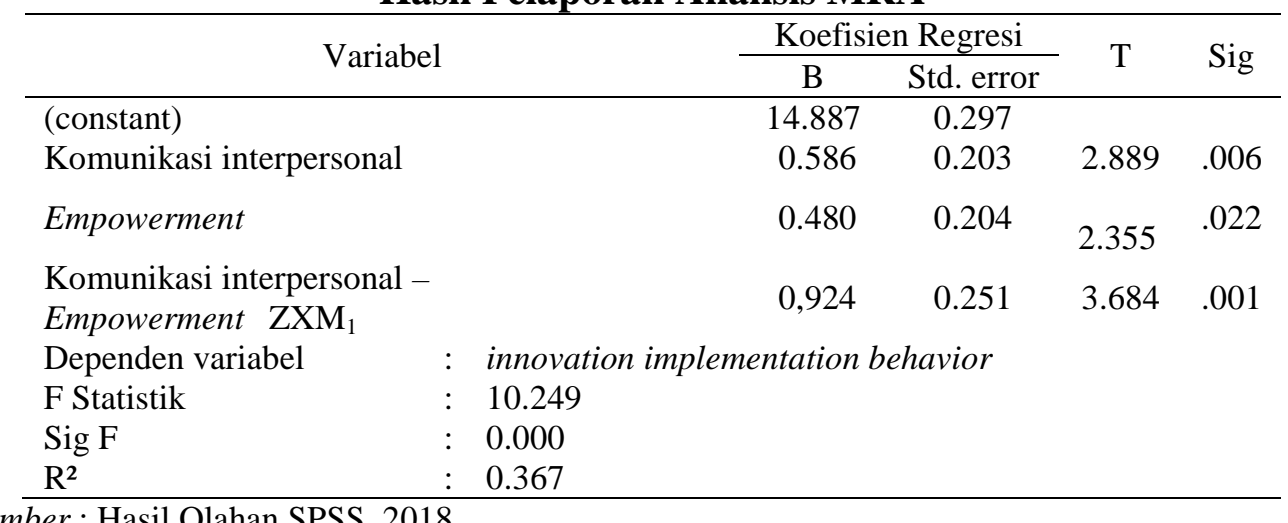

Persamaan regresi moderasi pada Tabel 10, dapat dijelaskan untuk setiap variabel hal-hal sebagai berikut:

$$
\mathrm{Y}=14,887+0,586 \mathrm{X}+0,480 \mathrm{M}|+0,924 \mathrm{ZXM}|
$$

Nilai konstanta yang diperoleh adalah sebesar 14,887 menunjukan bahwa apabila perubahan variabel bebas dan moderasi yaitu komunikasi interpersonal dan empowerment sama dengan nol atau bersifat konstan, maka implementasi inovasi behavior mengalami peningkatan di Sardine Restaurant Seminyak Bali. 
Nilai Koefisien $\beta_{1}$ yang diperoleh sebesar 0,586 menunjukan bahwa interaksi antara variabel komunikasi interpersonal dan implementasi inovasi behavior bersifat positif. Artinya interaksi komunikasi interpersonal berpengaruh terhadap implementasi inovasi behavior mengalami peningkatan di Sardine Restaurant Seminyak Bali.

Nilai Koefisien $\beta_{2}$ yang diperoleh sebesar 0,480 menunjukan bahwa interaksi antara variabel empowerment dan implementasi inovasi behavior bersifat positif. Artinya interaksi empowerment berpengaruh terhadap implementasi inovasi behavior mengalami peningkatan di Sardine Restaurant Seminyak Bali.

Nilai Koefisien $\beta_{4}$ yang diperoleh sebesar 0,924 menunjukan bahwa interaksi antara variabel empowerment, komunikasi interpersonal dan implementasi inovasi behavior bersifat positif. Artinya interaksi empowerment memperkuat pengaruh komunikasi interpersonal berpengaruh terhadap implementasi inovasi behavior mengalami peningkatan di Sardine Restaurant Seminyak Bali.

Berdasarkan hasil dari koefisien jalur pada hipotesis penelitian, maka dapat dijabarkan hubungan kausal antar variabel komunikasi interpersonal yang dimoderasi oleh empowerment terhadap implementasi inovasi behavior sebagai berikut.

Hasil uji parsial menunjukan bahwa komunikasi interpersonal berpengaruh positif dan signifikan terhadap implementasi inovasi behavior di Sardine Restaurant Seminyak Bali. Devito (2011: 98) menjelaskan komunikasi jenis ini dianggap paling efektif dalam upaya mengubah sikap, pendapat atau perilaku 
seseorang, karena sifatnya yang dialogis berupa percakapan dengan keterbukaan, penerimaan informasi, mengatur pembicaraan, rasa saling menghardai sehingga timbulnya rasa umpan balik antara satu sama lain secara positif.

Hasil penelitian ini sama dengan penelitian Kurnia (2015) menyatakan komunikasi interpersonal memiliki pengaruh positif terhadap implementasi inovasi behavior. Hal yang sama dinyatakan oleh Hassan et al. (2010) inovasi kreatif karyawan dapat dipengaruhi oleh komunikasi interpersonal secara positif. Manoela (2013) dalam penelitiannya membukitkan ada keterkaitan positif antara komunikasi interpersonal dengan implementasi inovasi behavior.

Hasil uji parsial menunjukan bahwa empowerment berpengaruh positif dan signifikan terhadap implementasi inovasi behavior di Sardine Restaurant Seminyak Bali. Teori identitas peran (Stryker dan Burke, 2000) menunjukkan bahwa seorang karyawan yang menggunakan pemberdayaan dengan cara yang positif cenderung menganggapnya pas dalam identitas perannya mengatur dan mengalami pemberdayaan psikologis yang lebih besar cenderung menunjukkan perilaku implementasi inovasi yang lebih tinggi.

Hasil penelitian ini sama dengan penelitian Muhdar et al. (2015) menyatakan dalam penelitiannya empowerment memiliki keterkaitan positif pada implementasi inovasi behavior. Hakan dan Jamel (2015) empowerment berpengaruh secara positif terhadap implementasi inovasi behavior. Rella et al. (2015) menyatakan empowerment secara positif mampu meningkatkan inovasi karyawan yang kreatif. Barbara et al. (2014) dalam penelitiannya menunjukkan 
lima aspek pemberdayaan psikologis memberikan dampak positif untuk meningkatkan implementasi inovasi behavior.

Hasil uji parsial menunjukan bahwa empowerment memoderasi pengaruh positif dan signifikan komunikasi interpersonal terhadap implementasi inovasi behavior di Sardine restaurant Seminyak Bali. Pemberdayaan (empowerment) adalah suatu proses dalam rangka menciptakan kekuatan atau kemampuan seseorang atau beberapa orang, sehingga dapat melakukan suatu pekerjaan baik menggunakan fisik (tenaga) maupun menggunakan akal (pikiran) untuk menghasilkan sesuatu yang dapat dimanfaatkan dalam kehidupan manusia yang menyangkut dengan pekerjaannya melalui ide-ide kreatif secara inovatif dengan komunikasi interpersonal secara efektif (Rella et al., 2014).

Hasil penelitian ini sama dengan penelitian Barbara et al. (2014) dalam penelitiannya menunjukkan lima aspek pemberdayaan psikologis memberikan dampak positif dan berkorelasi dengan motivasi intrinsik komitmen karyawan yang diterapkan dengan dalam bentuk implementasi inovasi behavior. Muhdar et al. (2015) menyatakan dalam penelitiannya empowerment memiliki keterkaitan positif pada implementasi inovasi behavior. Hakan dan Jamel (2015) empowerment sebagai variabel memoderasi komunikasi interpersonal secara positif terhadap implementasi inovasi behavior. Rella et al. (2015) menyatakan empowerment mampu memoderasi secara positif peningkatan inovasi karyawan secara kreatif dengan komunikasi interpersonal. 
Ade Pramana Kusdi Putra, Peran Empoworment dalam.....

\section{SIMPULAN DAN SARAN}

Komunikasi interpersonal berpengaruh positif dan signifikan terhadap implementasi inovasi behavior pada karyawan Sardine Restaurant Seminyak Bali, artinya komunikasi yang efektif mampu meningkatkan implementasi inovasi behavior karyawan.

Empowerment berpengaruh positif dan signifikan terhadap implementasi inovasi behavior pada karyawan Sardine Restaurant Seminyak Bali, artinya pelaksanaan empowerment secara berkesinambungan akan meningkatkan implementasi inovasi behavior karyawan.

Empowerment memoderasi pengaruh positif komunikasi interpersonal terhadap implementasi inovasi behavior pada karyawan Sardine Restaurant Seminyak Bali, artinya empowerment yang terlaksana dengan baik berperan penting untuk melaksanakan komunikasi interpersonal yang efektif sehingga menciptakan implementasi inovasi behavior karyawan.

Pihak manajemen harus memperhatikan indikasi permasalahan komunikasi interpersonal yang terjadi antar karyawan, dimana minimnya rasa kerja sama yang ditunjukkan dengan sikap kurangnya rasa saling menghargai satu sama lain, hal ini harus segera di atasi oleh pihak manajemen dalam hal melakukan pertemuanpertemuan rutin, mengadakan family gathering sehingga satu sama lain karyawan lebih mengenal dengan komunikasi yang baik untuk menciptakan rasa saling menghargai dalam melaksanakan pekerjaan.

Pihak manajemen harus memperhatikan indikasi permasalahan yang dihadapi karyawan dalam pelaksanaan empowerment menyangkut tingkah laku 
karyawan, maka dari itu perusahaan harus membina karyawannya dengan melakukan pembelajaran untuk menyelesaikan pekerjaan sehingga memiliki kreasi tersendiri dalam menyelesaikan pekerjaan baik itu di kitchen, weaters, booking table dll.

\section{REFERENSI}

Ahmad Zubaidi, (2014). The Influence Of Servant Leadership and Bureaucracy Apparatus Behavior to The Service Performance In Resettlement Are in DKI Jakarta. The International Journal Of Social Sciences. 27(1): 11-25

Ari Fadzilah, (2006). Analisis Pengaruh Pemberdayaan Karyawan dan Self of Efficacy Terhadap Kinerja bagian Penjualan (Studi kasus pada PT. Sinar Sosro Wilayah Pemasaran Semarang). Jurnal studi Manajemen dan Organisasi.3(1): 12-27

Astohar, (2012). Kepemimpinan Pelayanan (Servant Leadership) sebagai Gaya Kepemimpinan Untuk Kemajuan Organisasi. Jurnal Ilmu Manajemen dan Akuntansi Terapan. 3(2): 51-65

Barbara Van Winkle, Stuart Allen, Douglas DeVore, Bruce Winston, (2014). The Relationship Between the Servant Leadership Behaviors of Immediate Supervisors and Followers' Perceptions of Being Empowered in the Context of Small Business. Journal of Leadership Education. 13(13): 7082

Bjorn Michaelis, Ralf Stegmaier dan Karlheinz Sonntag, (2009). Affective Commitment to Change and Innovation Implementation Behavior: The Role of Charismatic Leadership and Employees' Trust in Top Management. Journal of Change Management. 9(4): 399-417

David E. Melchar and Susan M. Bosco, (2010). Achieving High Organization Performance through Servant Leadership. The Journal of Business Inquiry. 9(1): $74-88$

Devito, A. Joseph. (2011). Komunikasi Antarmanusia. Tanggerang Selatan: Karisma Publishing Group

Eko Nusantoro, (2012). Optimalisasi Pemberdayaan Sumber Daya Manusia Dalam Lingkungan Bekerja. Jurnal Manajemen Kewirausahaan. 3(1): 112 
Hakan Erkutlu dan Jamel Chafra, (2015). The effects of empowerment role identity and creative role identity on servant leadership and employees' innovation implementation behavior. Journal Procedia - Social and Behavioral Sciences. 18(1): 3-11

Hendri Kwistianus dan Devie, (2015). Pengaruh Servant Leadership Terhadap Employee Empowerment, Organizational Culture, dan Competitive Advantage Pada Universitas di Surabaya. Jurnal Business Accounting Review. 3(2): 191-200

Hassan Zarei Matin, Golamreza Jandaghi, Fateme Haj Karimi, and Ali Hamidizadeh, (2010). Relationship between Interpersonal Communication Skills and Organizational Commitment (Case Study: Jahad Keshavarzi and University of Qom, Iran). European Journal of Social Sciences. 13(3): 387-39

Izani Bin Ibrahim dan Yahya Bin Don, (2014). Servant Leadership and Effective Changes Management in Schools. International Journal of Scientific and Research Publications. 4(1): 1-9

Kamus Bahasa Indonesia. (2008). Jakarta, Balai Pustaka.

Khan, Sharafat. (1997). They Key to being a Leader Company: Empowerment. Journal Personality and Partisipation. 3(1): 44-45

Kok Pooi Chen, (2011). A Study on The Impact of Empowerment on Employe Performance in The Automotive Industry In Malaysia. International Journal of Human Resource Management. 3(2): h: 1-34

Kurnia Atdi Anto, (2015). The Mediating Role of organizational Commitment In Influence Relationships Between Interpersonal Communication and Emotional Intelligence Toward Employee Performance. International Journal of Business, Economics and Law. 7(2): 47-56

Luthans, Fred. (2011). Perilaku Organisasi. Edisi kesepuluh. Penerbit Andi Offset.

Lora Reed, (2015). Servant Leadership, Followership, and Organizational Citizenship Behaviors in 9-1-1 Emergency Communications Centers:Implications of a National Study. International Journal Of Servant Leadership: Theory and Practice. 2(1): 71-94

Manoela Popescu, (2013). Interpersonal Communication Relevance to Professional Development, in Social Systems. International Journal of Academic Research in Business and Social Sciences. 3(4): 370-375 
Muhdar H.M., Mahlia Muis, Ria Mardiana Yusuf dan Nurjannah Hamid, (2015). The Influence of Spiritual Intelligence,Leadership, and Organizational Culture on Organizational Citizenship Behavior and Employees Performance (A Study on Islamic Banks in Makassar, South Sulawesi Province, Indonesia). The International Journal Of Business \& Management. 3(1): 297-314

Orebiyi, A. O. (2011). the influence of Interpersonal Communication on Secondary School Teachers' Job Satisfaction and three types of Commitments in Kogi State, Nigeria. Journal of Communication and Culture: International Perspective. 2(1): 109-117

Pek Nike Oktavia dan Devie, (2014). Analisis Dampak Servant Leadership terhadap Competitive Advantage. Jurnal Business Accounting Review. 2(2): 244-251

Rahmawati, Sri Murni, Siti Supeni, Antonius Sriyanto, dan Eko. (2014). Sistem Inovasi Daerah Wonogiri untuk Memberdayakan Masyarakat dengan Keunggulan Daerah. Journal Ekonomi and Business Research. 3(2): 789796

Rella Mart Diana Dewi, Gusti Ayu dan Mohamad Yusak Anshori, (2014). Peningkatan Inovasi melalui Empowerment sebagai Penerapan Entrepreneurship. Jurnal Entrepreneur dan Entrepreneurship. 3(2): 119132

Robbins, Stephen P. 2008. Organizational Behavior. Tenth Edition. Edisi Bahasa Indonesia. PT Indeks Kelompok Gramedia.

Russell, R.F. \& Stone, A.G. (2002). A review of servant leadership attributes: developing a practical model. Leadership \& Organization Development Journal. 23(3): 145-157

Spreitzer, G.M. (1995). Psychological empowerment in the workplace: dimensions, measurement and validation. Academy of Management Journal. 38 (5): 1442-1465

Syahfarnas Adi Putrantoro, (2014). Pengaruh kepemimpinan, komitmen organisasi dan komunikasi interpersonal terhadap Organizational Citizenship Behavior (OCB) Anggota Rotaract Club Semarang. Ekonomika dan Bisnis Universitas Diponegoro. 9(2):1-61

Sugiyono. (2013). Metode Penelitian Bisnis. Bandung: CV Alfabeta. 